\title{
Modified comb-shaped antisense oligonucleotides may secure us against many important viral diseases including AIDS
}

Ahmed Ibrahim ( $\sim$ shamranis60@gmail.com )

The National Ribat University

\section{Biological Sciences - Article}

Keywords:

Posted Date: December 29th, 2021

DOI: https://doi.org/10.21203/rs.3.rs-1207172/v1

License: (c) (1) This work is licensed under a Creative Commons Attribution 4.0 International License.

Read Full License 


\section{Abstract}

To inhibit HIV replication and infection, we have designed novel linear single stranded modified antisense nucleic acid oligonucleotides ending with or without chain terminating bases (Which resemble the shape of the comb). They were targeting specifically the HIV-1 clone pNL4-3 strong promoter pre PBS region to stop cDNA synthesis within or before the R region, preventing the viral reverse transcriptase (RT) jumping to the 3 ' end and continue copying the virus. The main advantages of our comb shaped oligonucleotides are their specificity and extreme protection against resistance by known viral mutations.

Promising results were obtained for two 15-mer compounds at one tenth azidothymidine concentration.

As a result we claim that when adapted properly, the comb shaped antivirals can be used to target the genomic RNA of a number of serious viruses such as for example Ebola, SARS-CoV-2, Influenza, Dengue, hepatitis $C$, Chikungunya and Zika as they are all using polymerases to copy their genomic RNA ${ }^{1-8}$. Their genomic RNA could be destroyed through the human or viral endonucleases instead of the viral RT RNAseH site when their polymerases are stopped at specific sites.

\section{Main Text}

In 1987 the FDA approved Zidovudine, the first therapy against HIV which was a nucleoside reverse transcriptase inhibitor. By 1996, department of health and human services (DHHS) and the world health organization (WHO) recommended combining anti-HIV medicines; this combined treatment is called antiretroviral therapy ${ }^{9}$.

Anti-HIV drugs are organized into five classes based on the stage of the HIV life cycle they inhibit. As of 2019, there were 28 individual agents and 13 fixed dosed combination drugs targeting viral reverse transcriptase (RT), protease and integrase, as well as the cellular entry co-receptor CCR5 ${ }^{10}$.

Thirteen individual agents are reverse transcriptase inhibitors belonging to the nucleoside or nucleotide reverse-transcriptase inhibitors (NRTIs) category which lack 3' hydroxyl group on their ribose or ribose mimic moiety including Emtricitabine ${ }^{11}$, Lamivudine ${ }^{12}$, Abacavir $^{13}$, Di-adenosine, Stavudine, Zidovudine and Zalcitabine which has been discontinued ${ }^{14,15,16}$ or to the non-nucleoside or nucleotide reversetranscriptase inhibitors (NNRTIs) which bind into a hydrophobic pocket close to the polymerase active site and inhibit polymerization, including Rilpivirine, Etravirine,Delavirdine, Doravirine,Efavirenz and Nevirapine ${ }^{17}$.

All anti-HIV drugs are associated with a number of short- and long-term side effects ${ }^{18}$. Chronic HIV infection is associated with increased risk co morbidities. Lapses in medication adherence can lead to viral rebound and disease progression ${ }^{19}$ also HIV develops rapidly mutations that affect virus susceptibility to treatment ${ }^{20}$. 
For decades the possibility to use nucleic acids as antiviral therapeutics has been studied. In theory antisense oligonucleotides, ribozymes, DNAymes, and aptamers can trigger sequence specific inhibition of particular mRNA transcripts including the viral genomes. However difficulties with their efficiency, offtarget effects, toxicity, delivery and stability halted their development and use in the clinic ${ }^{21}$.

GEM (gene expression modulator) 91 is a 25 -mer phosphorothioate (PS) oligonucleotide complementary to the HIV-1 gag initiation site with multiple inhibitory mechanisms ${ }^{22}$. The non-sequence dependent inhibition of virus entry and reverse transcription were due to a poly-anionic effect of the PS backbone. GEM 91 intracellular RNase $\mathrm{H}$ cleavage was inefficient as its free uptake was almost restricted to endosomal vesicles within the cytosol ${ }^{23}$. PS oligonucleotides nuclear delivery was efficiently improved with cationic lipids inducing higher antisense activity ${ }^{24}$.

Hybridon developed GEM-92, a second generation oral phosphorothioate gapmer directed against the gag gene in HIV-1 mRNA maintaining the ability to induce RNA cleavage by RNase $\mathrm{H}$ with great protection against nucleases and a higher RNA binding ${ }^{25}$. However, no second generation and only a single first generation antisense oligonucleotide (Fomiversin), for the treatment of CMV-induced retinitis in AIDS patients, have been clinically approved ${ }^{26}$.

With advances that have been made in small RNAs systemic delivery, they may soon be evaluated for use in combination drug therapy ${ }^{27}$. Examples include the small activating RNAs which are double stranded RNAs able to activate gene expression ${ }^{28}$, the short hairpin RNAs, RNA decoys and aptamers as well as ribozymes that mediate cleavage ${ }^{29,30}$.

It is clear that finding new drugs or virucides against HIV-1 infection and AIDS as well as other viral diseases remains a top priority especially in our recent Corona time.

Our design provides compounds intended to stop cDNA synthesis before or at the R region of HIV-1 clone pNL4-3 (GenBank accession No. M19921.2). they prevent RT from continuing CDNA synthesis from the 3' end as no or small part of the $\mathrm{R}$ region is going to be transcribed, the last 3 ' base in these compounds could be a chain terminating base. It is difficult for RT RNAse $\mathrm{H}$ site or nucleases to break these compounds down and continue transcription and synthesis as they are modified to resist breaking in all breakable positions.

All mutations that affect RT, protease, integrase as well as envelop gene can't affect them.as they target the pre-PBS region which is a highly conserved region. Moreover, any possible mutations such as SNPs will not affect them as they are polynucleotides. The suspected lower resistance may allow such compounds to have virucidal activity when a suitable dose is used.

Our compounds have a good stability, water solubility and sequence specificity and could be more improved to be druggable and may constitute a nucleus of a new type of antiviral compounds. 


\section{Main References}

1. Honen, T., Groseth, A., \& Feldmann, H. (2019). Therapeutic strategies to target the Ebola virus life cycle. Nature reviews Microbiology, 17(10), 593-606.

2. Trougakos, I. P., Stamatelopoulos, K., Terpos, E., Tsitsilonis, O. E., Aivalioti, E., Paraskevis, D., ... \& Dimopoulos, M. A. (2021). Insights to the SARS-CoV-2 life cyle pathophysiology and rationalized treatments that target COVID-19 clinical complications. Journal of biomedical science, 28(1), 1-18.

3. Zhao, b., Yi, G., Chuang, Y. C., Vaughan, R. C., Sankaran, B., ...\& Li, P. (2017). Structure and function of the Zika virus full -length NS5 protein. Nature communications, 8 (1), 1-9.

4. Guilligay, D., Tarendeau, F., Resa-Infante, P., Coloma, R., Crepin, T., Sehr, P. ...\& Cusack, S. (2008). The structure basis for cap binding by influenza virus polymerase subunit PB2. Nature structural \& molecular biology, 15(5), 500-506.

5. Deng, T., Sharps, J., Fodor, E., \& Brownlee, G. G. 2005). In vitro assembly of PB2 with a PB1-PA dimer supports a new model of assembly of influenza $A$ virus polymerase subunits into a functional trimeric complex. Journal of virology, 79(13), 8669-8674.

6. Bressanelli, S., Tomei, L., Rey, F. A., \& De Francesco, R. (2002). Structural analysis of the hepatitis C virus RNA polymerase in complex wth rbonucleotides. Journal of virology, 76(7),3482-3492.

7. Shimizu, H., Saito, A., Mikuni, J., Nakayama, E. E., Koyama, H., Honma, T., ... \& shioda, T. (2019). Discovery of a small molecule inhibitor targeting dengue virus NS5 RNA-dependent RNA polymerase. Plos neglected tropical diseases, 13(11), e0007894.

8. Xu, H. T., Colby-Germinario, S. P., Hassounah, S. A., Fogarty, C., Osman, N., Palanisamy, N., ... \& Wainberg, M. A. (2017). Evaluation of Sofosbuvir ( $\beta$-D-2'-deoxy-2'-a-flouro-2'- $\beta$-C-metylurdine) as an inhibitor of Dengue virus replicaion. Scientific reports, 7(1), 11-11.

9. Ghildiyal, R., Gupta, S., Gabrani, R., Joshi, G., Gupta, A., Chaudhary, V. K., \& Gupta, V. (2019). In silico study of chicungunya polymerase, a potential target for inhibitors. Virusdisease, 30(3), 394-402.

10. Kemnic, T. R., \& Gulick, P. G. (2020). HIV antiretroviral therapy. Statpearls [internet].

11. Bang, L. M., \& Scott, L. J. (2003). Emtricitabine. Drugs, 63(22), 2413-2424.

12. Johnson, M, A., Moore, K. H., Yuen, G. J., Bye, A., \& Pakes, G. E. (1999). Clinical pharmacokinetics of lamivudine. Clinical pharmacokinetics, 36(1), 41-66.

13. Hetherington, S., McGuirk, S., Powell, G., Cutrell, A., Naderer, O., Spreen, B., ... \& Steel, H. (2001). Hypersensitivity reactions during therapy with the nucleoside reverse transcriptase inhibitor abacavir. Clinical therapeutics, 23(10), 1603-1614.

14. Walker, U. A., Bauerle, J., Laguno, M., Murillas, J., Mauss, s., Schmutz, G., ...\& Mallolas, J. (2004). Depletion of mitochondrial DNA in liver under antiretroviral therapy with di-adenosine, stavudine or zalcitabine. Hepatology, 39(2), 311-317.

15. Whittington, R., \& Brogden, R. N. (1992). Zalcitabine. Drugs, 44(4), 656-683.june 24, 2019.

16. Cihlar, T., \& Ray, A. s. (2010). Nucleoside and nucleotide HIV reverse transcriptase inhibitors: 25 years after zidovudine. Antiviral research, 85 (1), 39-58. 
17. Elsafadi, Y., Vivet-Boudou, V., \& Marquet, R. (2007). HIV-1 reverse transcriptase inhibitors. Applied microbiology and biotechnology, 75(4), 723-737.

18. Stolk, L. M., \& Lüers, J. F. (2004). Increasing number of anti-HIV drugs but no definite cure Review of anti-HIV drugs. Pharmacy world and science, 26(3), 133-136.

19. Schozl, E. M., \& Kashuba, A. D. (2021). The lymph node reservoir: physiology, HIV infection, and antiretroviral therapy Clinical pharmacology and therapeutics, 109(4), 918-927).

20. Wensing, A. M., Calvez, V., Günthard, H. F., Johnson, V. A., Paredes, R., Pillay, D... \& Richman, D. D. (2016). 2017 update of the drug resistance mutations in HIV-1. Topics in antiviral medicine, 24(4), 132.

21. Haasnoot, J. and Berkhout, B. (2009). Nucleic acids-based therapeutics in the battle against pathogenic viruses. Antiviral strategies 243-263.

22. YAMAGUCHI, K., PAPP, B., ZHANG, D., ALI, A. N., AGRAWAL, S., \& BYRN, R. A. (1997). The multiple inhibitory mechanisms of GEM $91 \AA$, a gag antisense phosphorothioate oligonucleotide, for human immunodeficiency virus type 1. AIDS research and human retroviruses, 13(7), 545-554.

23. Lisziewicz, J., Sun, D., Weichold, F. F., Thierry, A. R., Lusso, P. A. O. L. O., Tang, J. ... \& Agrawal, S. (1994). Antisense oligodeoxynucleotide phosphorothioate complementary to Gag mRNA blocks replication of human immunodeficiency virus type 1 in human peripheral blood cells. Proceedings of the National Academy of Sciences, 91(17), 7942-7946.

24. Bennett, C. F., Chiang, M. Y., Chan, H. E. D. Y., Shoemaker, J. E., \& Mirabelli, C. K. (1992). Cationic lipids enhance cellular uptake and activity of phosphorothioate antisense oligonucleotides. Molecular pharmacology, 41(6), 1023-1033.

25. Zheng, R. (1999). Technology evaluation: GEM-92, Hybridon Inc. Current opinion in molecular therapeutics, 1(4), 521-523.

26. Orr, R. M. (2001). Technology evaluation: fomivirsen, Isis Pharmaceuticals Inc/CIBA vision. Current opinion in molecular therapeutics, 3(3), 288-294.

27. Gatignol, A., \& Scarborough, R. (2018). U.S. patent No 9,932,364. Washington, DC:US. Patent and trademark Office.

28. Ghabarian, H., Aghamiri, s., Eftekhary, M., Wagner, N., \& Wagner, K. D.(2021). Small activating RNAs: Towards the development of new therapeutic Agents and clinical Treatments. Cells, 10 (3), 591.

29. Fowler, L., \& Saksena, N. K. (2013). Micro-RNA: New players in HIV-pathogenisis, diagnosis, prognosis and ant-vral therapy. AIDS reviews, 15(1), 3-14.

30. Goguen, R. P., Malard, C. M., Scarborough, R. J., \& Gatignol, A. (2019). Small RNAs to treat human immunodeficiency virus type 1 infection by gene therapy Current opinion in virology 38, 0-20.

\section{Methods}

Four Comb shaped antisense compounds overlapping the strong promoter region of HIV-1 (oligos 1-4) and two scrambled controls (oligo 5 and 6 ) were custom synthesized by Biosynthesis incorporation, 
Texas, USA. At the time of experiment they were briefly centrifuged and re-suspended in non-DEPC-treated water at a concentration of $1 \mathrm{mM}$. Sequences are given in table 1.

\begin{tabular}{|c|c|c|c|c|c|c|}
\hline $\begin{array}{l}\text { Compound } \\
\text { Id }\end{array}$ & sequence & length & Position & $\begin{array}{l}\text { Mass } \\
\mu \mathrm{g}\end{array}$ & TM & $\begin{array}{l}\text { Dilution } \\
\text { volume }(\mu l) \\
\text { for } 1 \\
\text { millimolar } \\
\text { stock }\end{array}$ \\
\hline 1 & $5^{\prime}-T^{*} f C^{*}[e A]^{*} A G G C A^{*} A^{*}+G^{*} C$ & 11 & $80-90$ & 65.44 & 34.0 & 19.25 \\
\hline 2 & $5^{\prime}-T^{*} f C^{*}[e A] * A G G C A^{*} A^{*}+G *[d d C]$ & 11 & $80-90$ & 65.15 & 34.0 & 19.16 \\
\hline 3 & $\begin{array}{l}5-A * f C * G G * G f C * A f C * A f C \\
* A C * T *+A * C-3\end{array}$ & 15 & $100-114$ & 66.18 & 44.7 & 14.27 \\
\hline 4 & $\begin{array}{l}5^{\prime}-A * f C * G G * G f C * A f C * A f C \\
* A C * T *+A *[d d C]-3\end{array}$ & 15 & $100-114$ & 65.96 & 44.7 & 14.23 \\
\hline 5 & $5^{\prime}-C^{*} A^{\star} A * G+G f C[e A] T{ }^{*} C * G * A$ & 11 & - & 64.21 & 34.0 & 18.89 \\
\hline 6 & $\begin{array}{l}5^{\prime}-G * G^{*} f C A^{*} f C G * C+A * f C A * f C A \\
{ }^{*} A * C * T-3{ }^{\prime}\end{array}$ & 15 & -- & 67.39 & 44.7 & 14.54 \\
\hline
\end{tabular}

Where: $+N$ (eg: $+A,+C,+G$ and $+T$ ) represents $B N A$; * represents phosphorothioate; $f N$ represents 2'fluoro RNA; eN represents 2'-0 methoxy ethyl

We have used a colorimetric (Roche) cell free HIV reverse transcriptase assay which takes advantage of the ability of reverse transcriptase (RT) to synthesize DNA starting from a viral template.

Digoxigenin- and biotin-labeled nucleotides were incorporated into the RT-synthesized DNA molecule. Then, the detection and quantification of synthesized DNA (as a parameter for RT activity) was done using a sandwich ELISA protocol: Biotin-labeled DNA binds to the surface of micro-plate (MP) modules that have been precoated with streptavidin. In the next step, an antibody to digoxigenin conjugated to peroxidase (anti-DIG-POD) binds to the digoxigenin-labeled DNA. In the final step, the peroxidase substrate ABTS was added. The peroxidase enzyme catalyzes the cleavage of the substrate, producing a colored reaction product ${ }^{1,2}$. The intensity of the color product was then determined using an ELISA reader and is directly correlated to the level of RT activity in the sample (Figure 2).

\section{Cloning the strong promoter region of HIV}

The strong promoter region of HIV-1 was obtained by PCR amplification and cloned into pcDNA3.1DNA using primers: 5'-ATCGGTACCGCCACCTGGAAGGGCTAATTTGG-3' and 5' TTGCGGCCGCCTCGCACCCATCTCTCTCC-3' (Figure 3). 
After PCR amplification, the DNA was purified using the Qiaquick PCR purification kit (Qiagen), then digested using restriction enzymes $\mathrm{Kpnl}$ and Notl, and cloned into a linearized pcDNA3.1 vector (prepared using $\mathrm{Kpnl}$ and Notl) using standard cloning techniques ${ }^{3}$ and DH5a competent cells ${ }^{4}$. The resulting construct was confirmed by the colony PCR technique and DNA sequencing. Single bacterial colonies carrying the HIV-1-promoter- pcDNA3.1 vector were used to initiate an overnight liquid culture to amplify the plasmid DNA which was isolated and purified using Qiagen Maxi-Prep kit.

\section{RNA Transcription}

The plasmid (HIV-1-promoter-pcDNA3.1) was linearized using Xhol (NEB), then purified by phenol/chloroform extraction and ethanol precipitation and dissolved in nuclease-free water. The

mMESSAGEmMACHINE T7 Ultra transcription kit (Invitrogen) ${ }^{\mathbf{5}}$, was used to generate the replicon RNAs in the correct orientation from the linearized vector according to manufacturer's instruction. The synthesized RNA was purified by phenol:chloroform extraction and isopropanol precipitation.

\section{Quantification of the inhibitory effect of the comb-shaped antisense oligonucleotides}

To quantify the inhibitory effect of the test oligonucleotides against HIV-1 RT, we used the Reverse Transcriptase Assay, Colorimetric kit (HIV RT assay kit, Roche USA Cat. No.11 468120 910), following the manufacturer's instructions ${ }^{6}$.

Recombinant HIV-1 RT (4 ng) was diluted in lysis buffer (Tris-buffer: $50 \mathrm{mMTris,} 80 \mathrm{mM}$ potassium chloride, $2.5 \mathrm{mM}$ DTT, $0.75 \mathrm{mM}$ EDTA and $0.5 \%$ Triton X-100, pH 7.8) in a reaction tube. dATP, dGTP, and dCTP $(30 \mu \mathrm{M})$ were added to $1 \mathrm{ml}$ of incubation buffer together with the kitprovided vial-3 [containing Tris-HCl (50 mM, pH 7.8), DIG-dUTP, biotin-dUTP, and dTTP]. Template RNA $(1 \mu \mathrm{g})$ and $10 \mu \mathrm{M}$ of OligodT (reaction mixture) were then added. This is termed 'the reaction mixture.'

Next, we added the test oligos at $0.5,5 \& 50 \mu \mathrm{M}$ concentration to the reaction mixture and incubated them for $1 \mathrm{~h}$ at $37^{\circ} \mathrm{C}$. We also incubated the reaction mixture without any oligos, as our no-inhibitor control. Reaction mixture plus oligos with no HIV-1-RT was used as negative controls. These samples were then transferred to wells of the kit's Micro Plate module. The plate was covered and incubated for $1 \mathrm{~h}$ at $37^{\circ} \mathrm{C}$ and washed five times with wash buffer. Anti-DIG-POD (200 $\mu$ l working dilution) was added and incubated for $1 \mathrm{~h}$ at $37^{\circ} \mathrm{C}$. The plate was again washed five times with wash buffer. ABTS substrate solution $(200 \mu \mathrm{l})$ was added and incubated at room temperature for $30 \mathrm{~min}$ until a green color developed. The plate was then read at $405 \mathrm{~nm}$ in an ELISA reader. Lysis buffer without RT was used as a negative control and azidothymidine $(0.5 \mathrm{mM} \mathrm{AZT})$ with RT was used as a positive control.

\section{Results}

The resulting colorimetric signal intensity is directly proportional to the RT activity. Therefore, the inhibitory activity of the tested RT inhibitors can be expressed as the percent inhibition relative to a sample without inhibitor or the no-inhibitor control. 
Oligos 1 and 2 did not inhibit HIV-RT activity $(95 \pm 3.81 \%$ and $89 \pm 1.73 \%$ activities at $50 \mu \mathrm{M}$, respectively). Oligos 3 and 4 did inhibit HIV-RT activity (35 $\pm 1.72 \%$ and $56 \pm 4.58 \%$ activities at $50 \mu \mathrm{M}$, respectively). As expected, the scrambled antisense compounds did not inhibit HIV-RT activity ((97 \pm $0.97 \%$ and $98 \pm 0.70 \%$ activities at $50 \mu \mathrm{M}$, respectively). The positive control azidothymidine (AZT, 0.5 $\mathrm{mM}$ ) reduced HIV-RT activity to $25 \pm 1.68 \%$. Data are shown in Figure 4 and 5 .

\section{Conclusions}

We can conclude that under the conditions tested, both of the 15-mer comb shaped antisense compounds can inhibit the RT activity of the HIV-RT, with percentage reductions of $65 \%$ and $44 \%$, respectively, when used at a $50 \mu \mathrm{M}$ concentration. The 11-mer combs did not inhibit the RT activity; unfortunately modifications that increase their binding affinity increase the possible off target effects as they may bind mononucleotides such as the ATP and GDP as well as proteins increasing their toxicity.

\section{Methods References}

1. Eberle, J., \& Sebl, R (1992). A new method for measuring reverse transcriptase activity by ELSA. Journal of virological methods, 40(3), 347-356.

2. Suzuki, K., Craddock, B. P., Kano, T., \& Steigbigel, R. T. (1993). Colorimetric reverse transcriptase assay for HIV-1. Journal of virological methods, 41(1), 21-28.

3. Mahdavi, M., Ebtekar, M., Mahboudi, F., Korram Khorshid, H., Rahbarizadeh, F., Azadmanesh, K., ... \& Hassan, . M. (2009). Mmunogenecty of a new HIV-1 DNA construct in a BALB/c mouse model. Iranian journal of immunology, 6(4), 163-173.

4. Lin, J. J., Smith, M., Jessee, J., \& Bloom, F. (1992). DH1 1S: an Echerichia coli strain for preparation of single stranded DNA from phagemid vectors. Biotechniques, 12(5), 718-721.

5. Kit, H. Y. C. R. T. (2012). mMASSAGE mMACHINE® Kit.

6. Assay, R. T. Colorimetric Kit. Roche Diagnostics GmbH, Roche Applied Sience, Sandhofer Strasse, $116,13-68305$.

\section{Declarations}

\section{Acknowledgments}

I want to deeply thank Mr. RASHID ABDULLAH ALSHEHRI and Mr. SALEH ABDULLAH ALSHAMRANI for their financial, logistic and spiritual support. Without their support this work may not see the light or comes out.

I also want to acknowledge Biosynthesis incorporation, Texas, USA, \& Virology research services, London, UK. 
Figures

Figure 1

The suspected mechanism of the Comb shaped oligomers

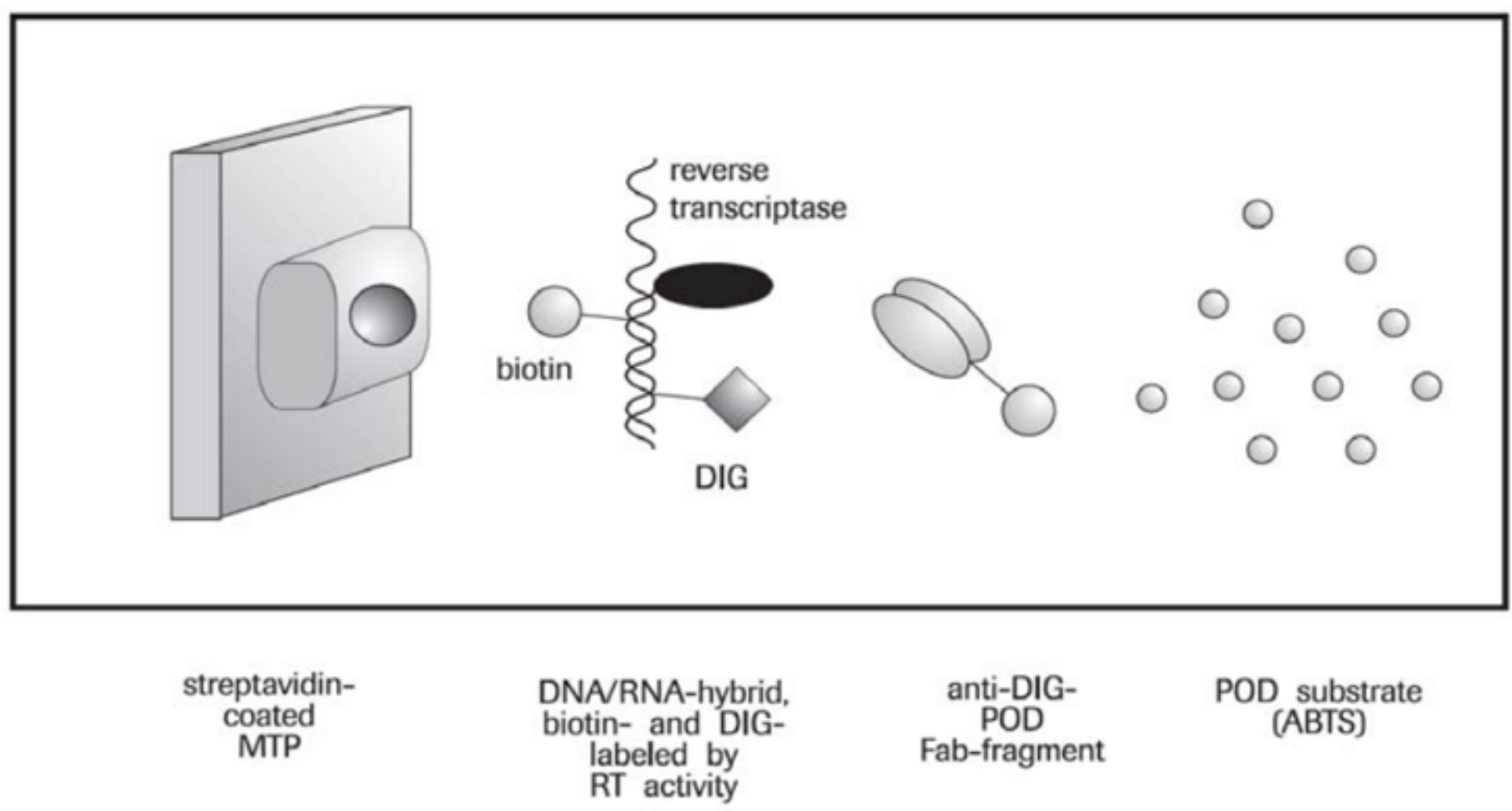

Figure 2

The cell-free HIV-RT assay test principle

Figure 3

Cloning of the HIV-1 strong promoter region 


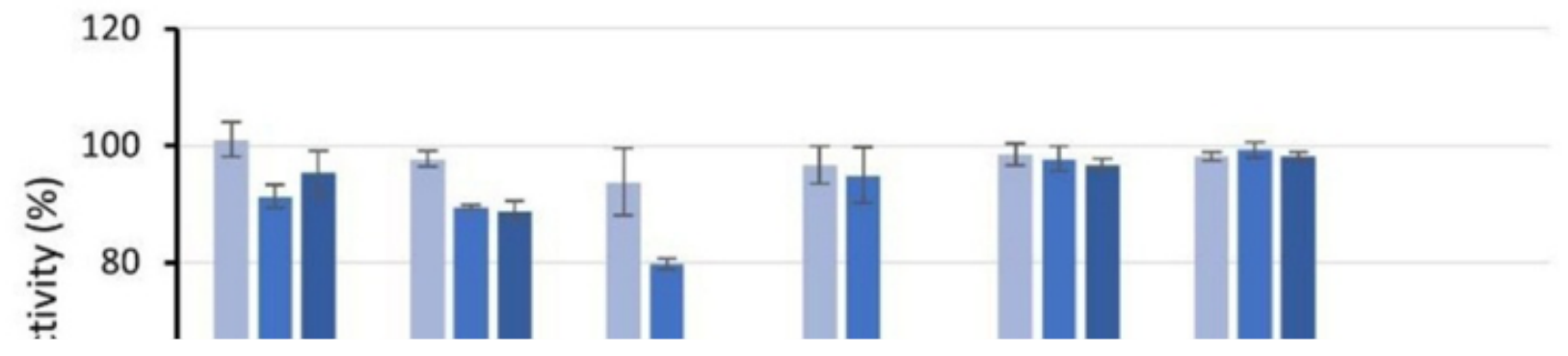

Figure 4

Relative RT activities (\%) of HIV-RT when treated with Oligos $1-6$ at concentrations of $0.5,5$, and $50 \mu \mathrm{M}$

Figure 5

Developed micro plate modules showing the RT activities, a stronger color corresponds to greater RT activity 